\title{
Improved chemotherapeutic efficacy of injectable chrysin encapsulated by copolymer nanoparticles
}

\author{
This article was published in the following Dove Press journal: \\ International Journal of Nanomedicine \\ 9 March 2017 \\ Number of times this article has been viewed
}

\author{
Kyoung Mee Kim ${ }^{1,2}$ \\ Hyun Kyung Lim $^{1,2}$ \\ Sang Hee Shim ${ }^{1,2}$ \\ Joohee Jung ${ }^{1,2}$ \\ 'College of Pharmacy, ${ }^{2}$ Innovative \\ Drug Center, Duksung Women's \\ University, Seoul, Republic of Korea
}

\begin{abstract}
Chrysin is a flavone that is found in several plants and in honeycomb and possesses various biological activities. However, its low solubility means it has poor bioavailability, which must be resolved to enable its pharmaceutical applications. In the present study, chrysin was incorporated into methoxy poly(ethylene glycol)- $\beta$-polycaprolactone nanoparticles (chrysin-NPs) using the oil-in-water technique in order to overcome problems associated with chrysin. The properties of chrysin-NPs were analyzed, and their anticancer effects were investigated in vitro and in vivo. Chrysin-NPs were $77 \mathrm{~nm}$ sized (as determined by dynamic laser light scattering) and showed a monodisperse distribution. The zeta potential of chrysin-NPs was $-2.22 \mathrm{mV}$, and they were spherically shaped by cryo-transmission electron microscopy (cryo-TEM). The loading efficiency of chrysin-NPs was $46.96 \%$. Chrysin-NPs retained the cytotoxicity of chrysin in A549 cells. The therapeutic efficacies of chrysin-NPs were compared with those of chrysin in an A549-derived xenograft mouse model. Chrysin-NPs were intravenously injected at a 10 times lower dosage than chrysin 3 times per week ( $22 \mathrm{~d} \times 3 /$ week). However, free chrysin was orally administrated 5 times per week (q1d $\times 5 /$ week). Chrysin-NP-treated group showed significant tumor growth delay, which was similar to that of chrysin-treated group, despite the considerably lower total dosage. These results suggest that the injectable chrysin-NPs enhance therapeutic efficacy in vivo and offer a beneficial formulation for chemotherapy.
\end{abstract}

Keywords: chrysin, nanoparticle, chemotherapeutic efficacy, non-small-cell lung cancer, in vivo model

\section{Introduction}

Lung cancer is the leading cause of cancer-related death in Korea and is among the leading causes of cancer-related death worldwide. ${ }^{1}$ In particular, non-small-cell lung cancer constitutes $85 \%$ of lung cancer cases and tends to develop resistance to chemotherapy. Thus, novel chemotherapeutic agents are needed to treat non-small-cell lung cancer.

Chrysin is a natural active component found in various herbs, mushroom, and propolis ${ }^{2}$ and has anti-inflammatory, ${ }^{3,4}$ antiaging, ${ }^{5}$ antiviral, ${ }^{6}$ antioxidant, ${ }^{7-9}$ antidiabetes, ${ }^{10}$ antiaromatase, ${ }^{11,12}$ and anticancer ${ }^{13-16}$ activities. Accordingly, it is widely held that chrysin has potential pharmaceutical applications. A combination of chrysin and cisplatin was reported to enhance anticancer effects in human malignant glioma cells, ${ }^{17}$ HepG2 cells, ${ }^{18}$ and drug-resistant cells. ${ }^{19}$ In a previous study, we reported that chrysin enhanced chemotherapeutic efficacy of docetaxel in a non-small-cell lung cancer model. ${ }^{15}$ However, the low solubility of chrysin means that its bioavailability is poor, and its half-life is only 13 min in human hepatocytes. ${ }^{20}$ Thus, these obstacles must be resolved before it can be used pharmaceutically. Currently, many researchers consider chrysin a drug sensitizer in integrative therapies because chrysin alone has low
Correspondence: Joohee Jung

College of Pharmacy, Duksung

Women's University, \#33, I44-gil,

Samyang-ro, Dobong-gu, Seoul 01369,

Republic of Korea

Tel +8229018731

$\mathrm{Fax}+8229018386$

Email joohee@duksung.ac.kr
International Journal of Nanomedicine 2017:12 1917-1925

1917 
chemotherapeutic efficacy. However, chemical modification of chrysin has become the focus of research attention in order to resolve the abovementioned problem. ${ }^{21}$ An oxidovanadium complex with chrysin was reported to improve chemotherapy in a colon adenocarcinoma model ${ }^{22}$ and in an osteosarcoma model. ${ }^{23}$ Furthermore, methoxy poly(ethylene glycol) (mPEG)-chrysin conjugates were reported to increase the encapsulation efficacy of doxorubicin and to enhance its anticancer effects. ${ }^{24}$ Poly(D,L-lactic-co-glycolic acid)-PEG (PLGA-PEG) has also been utilized to produce nanoparticles (NPs), including chrysin..$^{25,26}$ To date, chrysin formulations have mainly been investigated in vitro. Thus, evaluations of chrysin formulations and knowledge of the anticancer mechanism of chrysin in vivo are needed to aid drug development.

In this study, we formulated injectable chrysin-including NPs (chrysin-NPs) and evaluated them in non-small-cell lung cancer cells (A549 cells) and in an A549-xenograft model with a view toward their pharmaceutical applications.

\section{Materials and methods} Preparation of chrysin-NPs

Chrysin (Sigma-Aldrich, St Louis, MO, USA) was incorporated into copolymer NPs using an oil-in-water technique (Figure 1). mPEG- $\beta$-polycaprolactone copolymer
(mPEG-PCL, 50 mg; 2,000:5,200 Da; PolySciTech, West Lafayette, IN, USA) and $5 \mathrm{mg}$ of chrysin were dissolved in a dichloromethane (Duksan reagent, Gyeonggi-do, Korea) and methanol mixture (Duksan reagent; v/v, 1.5:1). This solution $(2.5 \mathrm{~mL})$ was added to a $1 \%$ aqueous polyvinyl alcohol solution $(6 \mathrm{~mL})$ and was emulsified by sonification for $1 \mathrm{~min}$. The solvent was removed by evaporation under stirring to produce NPs. To remove polyvinyl alcohol and surplus free chrysin, the supernatant was collected after centrifugation $(14,000 \mathrm{rpm})$ twice at room temperature for $1 \mathrm{~h}$.

\section{Characterization of chrysin-NPs}

Size distributions and zeta potentials of chrysin-NPs were determined by dynamic light scattering (DLS) using a Zetasizer Nano-ZS device (Malvern Instruments Ltd., Worcestershire, UK). Polydispersity index (PDI) represents a width parameter for the size-average as an intensity mean. Chrysin-NP morphology was observed by cryo-TEM (Cryo Tecnai F20; FEI Co., Hillsboro, OR, USA). Chrysin-loading efficiencies were calculated using Equation 1. Free nonencapsulated chrysin was dissolved in dimethyl sulfoxide (DMSO) (Sigma-Aldrich) and quantified by high-performance liquid chromatography (Agilent Technologies, Inc., Santa Clara, CA, USA) and confirmed at $348 \mathrm{~nm}$ using a microplate reader (Infinite M200 PRO; Tecan Inc., Grödig, Austria).

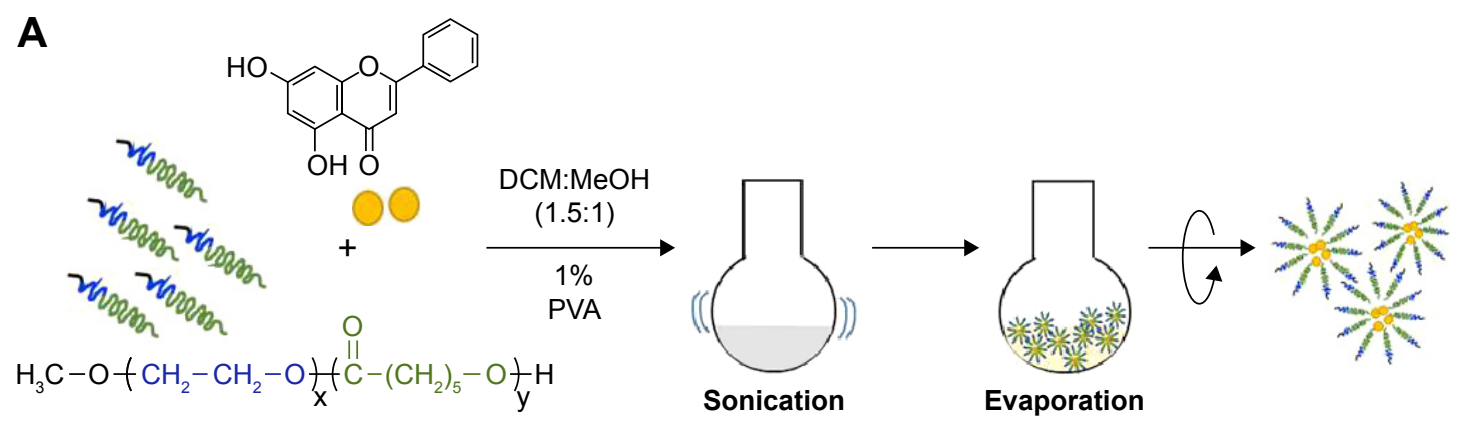

\section{B}

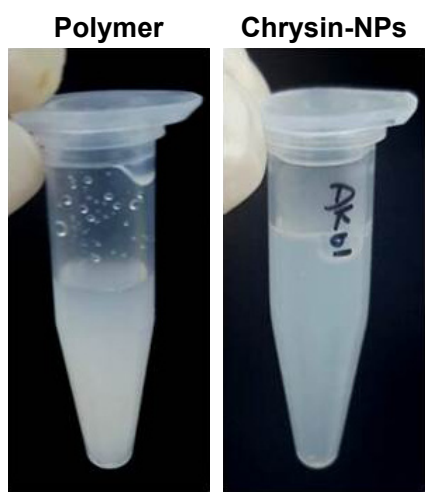

Figure I Schematic of the method used to produce NPs containing chrysin.

Notes: (A) Flowchart and structures of NPs containing chrysin. (B) Formulation of polymer and chrysin-NPs.

Abbreviations: NPs, nanoparticles; DCM, dichloromethane; PVA, polyvinyl alcohol. 
Chrysin-loading efficiency $(\%)=$

$$
1-\frac{\text { Free chrysin }}{\text { Total used amount of chrysin }} \times 100
$$

\section{In vitro release of chrysin from NPs}

Amounts of chrysin released by chrysin-NPs were determined after $0,1,4,8,12,24$, or $48 \mathrm{~h}$ with stirring at $37^{\circ} \mathrm{C}$ in phosphate-buffered saline (PBS, $\mathrm{pH} 7.4,0.1 \mathrm{M}$ ) by measuring absorbance at $348 \mathrm{~nm}$ using a microplate reader.

\section{Cell culture}

A549 cells (ATCC no CCL-185) were maintained in F-12K medium (Gibco, Grand Island, NY, USA) containing 10\% fetal bovine serum (GenDEPOT, Barker, TX, USA) and $1 \%$ penicillin/streptomycin (GenDEPOT) in a humidified $5 \% \mathrm{CO}_{2}$ atmosphere at $37^{\circ} \mathrm{C}$.

\section{MTT assay}

A549 cells (2,000 cells/well) were seeded in 96-well plates and incubated for $24 \mathrm{~h}$, and chrysin or chrysin-NPs were added for $48 \mathrm{~h}$. MTT (Sigma-Aldrich) was then added to media for $4 \mathrm{~h}$, and media were discarded. DMSO (SigmaAldrich) was added and absorbance $(560 \mathrm{~nm})$ was determined using a microplate reader (Infinite M200 PRO). The data represented average \pm standard deviation (SD; $\mathrm{n}=8$ ).

\section{In vivo tumor growth delay}

All animal experiments were performed according to a protocol approved beforehand by the institutional animal care and use committee of Duksung Women's University (No. 2015-017-005) in accordance with the guidelines of the care and use of laboratory animals, Duksung Women's University, Korea. A549 cells $\left(5 \times 10^{6}\right.$ cells/mice) were implanted subcutaneously into mice. The mice bearing an A549-derived tumor $100-150 \mathrm{~mm}^{3}$ in size were randomly divided to 3 groups ( $\mathrm{n}=5 /$ group). Chrysin $(50 \mathrm{mg} / \mathrm{kg}$ ) was orally (p.o.) administrated once a day, 5 times per week for 3 weeks, and chrysin-NPs $(5 \mathrm{mg} / \mathrm{kg}$ ) were intravenously injected every 2 days, 3 times per week for 3 weeks. Tumor sizes and mouse body weights were measured. Tumor volumes were calculated using the following equation.

$$
\text { Tumor volume }\left(\mathrm{mm}^{3}\right)=\left(\text { Length } \times \mathrm{Width}^{2}\right) \times 0.5
$$

The results are presented as mean $\pm \mathrm{SD}$ values.

\section{Tissue preparation for histological analysis}

After measuring final tumor sizes, tumor tissues were isolated from sacrificed mice and molded into optimal cutting temperature (OCT) compound (Leica, Nussloch, Germany). Frozen blocks were sliced to produce $5 \mu \mathrm{m}$ thick sections using a cryotome (Leica).

\section{TUNEL assay}

Sections were hydrated with $70 \%$ ethanol, bathed in 3\% $\mathrm{H}_{2} \mathrm{O}_{2}$ /distilled water (DW), washed with DW twice, incubated in DW at $60^{\circ} \mathrm{C}$ for $1 \mathrm{~h}$, cooled to room temperature, treated with terminal deoxynucleotidyl transferase (TdT) labeling buffer, and then incubated in TdT (Sigma)/biotinylated deoxyuridine (Roche Diagnostics, Mannheim, Germany) diluted in TdT labeling buffer for $1 \mathrm{~h}$ at $37^{\circ} \mathrm{C}$ in a humid chamber. The reaction was stopped using terminating buffer, and slides were washed with DW. The tissue sections were then blocked with $2 \%$ bovine serum albumin (BSA; bioWORLD, Dublin, OH, USA) in PBS, washed in PBS, incubated with $\mathrm{ABC}$ complex, washed with $0.05 \mathrm{M}$ Tris buffer, colorized with $\mathrm{DAB}$ (Vector laboratories, Inc., Burlingame, CA, USA), and examined under a Nikon eclipse microscope (Nikon Instruments Inc., Melville, NY, USA).

\section{Immunofluorescence staining}

Sections were washed with $1 \%$ BSA in PBS containing Tween $80(0.1 \% \mathrm{v} / \mathrm{v})$ twice, incubated with anti-Ki-67 antibody $(1: 100)$ overnight at $4{ }^{\circ} \mathrm{C}$, washed 3 times, incubated with Cy7-conjugated antimouse antibody (1:300) for $2 \mathrm{~h}$, and stained with 4',6-diamidino-2-phenylindol (DAPI) solution. Ki-67 staining was analyzed under a fluorescence microscope (DMi8, ×20, Leica).

\section{Western blot analysis}

Isolated tumor tissues were homogenized with radioimmunoprecipitation assay (RIPA) buffer (GenDEPOT) containing protease inhibitor and phosphatase inhibitor (GenDEPOT), and extracted proteins were quantified using a bicinchoninic acid (BCA) assay (Thermo Scientific, Waltham, MA, USA). Proteins were separated by $10 \%$ SDS-polyacrylamide gel electrophoresis (SDS-PAGE) and transferred to polyvinylidene fluoride (PVDF) membranes (Millipore, Darmstadt, Germany). Membranes were blocked with 5\% skimmed milk in tris-buffered saline with polysorbate 20 (TBST) $(50 \mathrm{mM}$ Tris- $\mathrm{HCl} \mathrm{pH} 7.4,150 \mathrm{mM} \mathrm{NaCl}, 0.1 \%$ Tween20), incubated with p53 antibody $(1: 1,000), \mathrm{p} 21$ antibody $(1: 1,000)$, or $\beta$-actin antibody $(1: 5,000)$ at $4{ }^{\circ} \mathrm{C}$, overnight, and then with secondary antibody $(1: 3,000)$ at room temperature for $3 \mathrm{~h}$. Blots were visualized using enhanced chemilumescent (ECL) solution and observed by ChemiDoc (FluorChemE, Germany). 

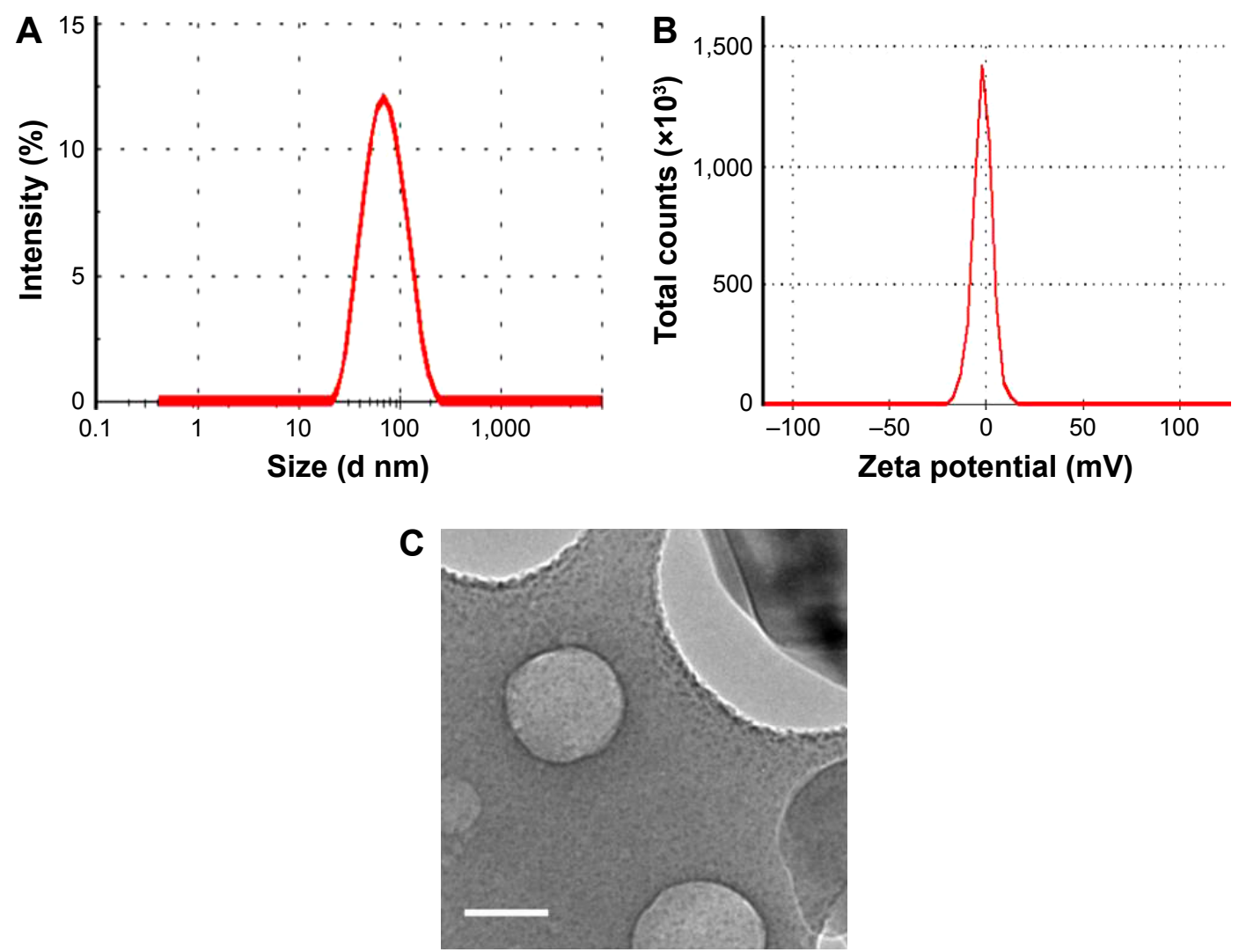

Figure 2 Physicochemical properties of chrysin-NPs.

Notes: The size distributions (A) and zeta potentials (B) of NPs and chrysin-NPs as determined by DLS. (C) Morphology of chrysin-NPs as observed by cryo-TEM. Scale bar, $100 \mathrm{~nm}$.

Abbreviations: NPs, nanoparticles; DLS, dynamic light scattering; TEM, transmission electron microscopy.

\section{Results}

\section{Characterization of chrysin-NPs}

Chrysin-NPs produced using the scheme shown in Figure 1A were yellowish in color in aqueous solution (Figure 1B). The polymer emulsion was white, but the inclusion of chrysin-NPs produced a yellow tint. The size distribution of chrysin-NPs indicated monodispersed particle as shown in Figure 2A. The average diameter of chrysin-NPs was $66.86 \mathrm{~nm}$ (PDI, 0.148) as determined by DLS (Table 1), and their zeta-potential was $-2.22 \mathrm{mV}$ (Figure 2B and Table 1). As shown in Figure 2C, chrysin-NPs were spherical and particle size observed by cryo-TEM agreed with DLSdetermined sizes. Chrysin-NPs exhibited a $46.96 \% \pm 1.12 \%$ encapsulation efficiency and $2.3 \mathrm{mg}$ of chrysin was incorporated into $50 \mathrm{mg}$ of NPs (4.6\%, loading percentage; Table 1$)$.
Additionally, the stability of chrysin-NPs remained at $4^{\circ} \mathrm{C}$ rather than $37^{\circ} \mathrm{C}$ (Figure S1).

\section{In vitro release of chrysin from chrysin- NPs}

Chrysin-NPs in PBS time-dependently released chrysin. During the early phase (the first hour), chrysin was rapidly released, but it was released slowly in the late phase. Passive release of chrysin in PBS without solubilizer for $48 \mathrm{~h}$ at $37^{\circ} \mathrm{C}$ was $50 \%$ (Figure 3 ).

\section{Cytotoxicity of chrysin-NPs}

Chrysin was previously reported to reduce cell viability in vitro. ${ }^{15}$ Thus, we investigated whether chrysin-NPs were as cytotoxic as free chrysin using A549 cells. As shown

Table I Characterization of chrysin-NPs

\begin{tabular}{lllll}
\hline & Size (PDI) & Zeta potential (SD) & Encapsulated efficiency & Loading content/polymer $^{\mathrm{a}}$ \\
\hline Chrysin-NPs & $77.15 \mathrm{~nm}(0.148)$ & $-2.22 \mathrm{mV}(4.9)$ & $46.96 \% \pm 1.12 \%$ & $2.3 \pm 0.05 \mathrm{mg} / 50 \mathrm{mg}$ \\
\hline
\end{tabular}

Note: ${ }^{2}$ Data were determined by dynamic light scattering.

Abbreviations: NPs, nanoparticles; PDI, polydispersity index; SD, standard deviation. 


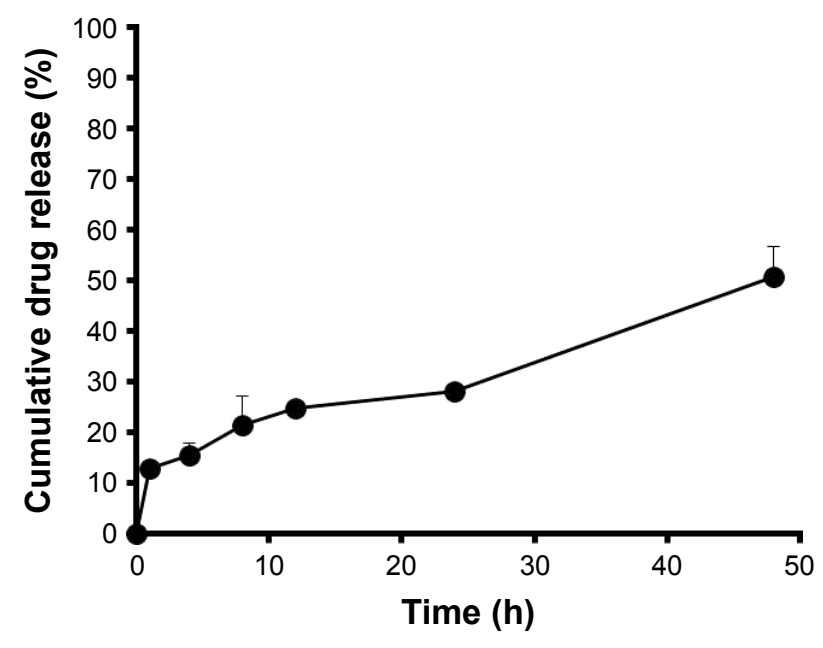

Figure 3 Effect of temperature on in vitro chrysin release.

Notes: Chrysin-NPs released chrysin in PBS, $p H$ 7.4. Results are mean \pm SD $(n=3)$. Abbreviations: NPs, nanoparticles; PBS, phosphate-buffered saline; SD, standard deviation.

in Figure 4, chrysin-NPs dose-dependently reduced cell viability. $\mathrm{IC}_{50}$ values of chrysin and chrysin-NPs were $6.89 \mu \mathrm{M}$ and $2.5 \mathrm{M}$, respectively. The cytotoxicity of chrysin-NPs was not as great as that of chrysin, suggesting that chrysin from NPs was more slowly taken up by cells. In addition, the cytotoxicity of chrysin-NPs was due to chrysin, not NPs. Nonloaded NPs were found to have no cytotoxic effect by clonogenic assay (Figure S2).

\section{Tumor growth delay by chrysin-NPs}

We investigated whether chrysin-NPs could improve therapeutic efficacy of chrysin using an A549-derived xenograft

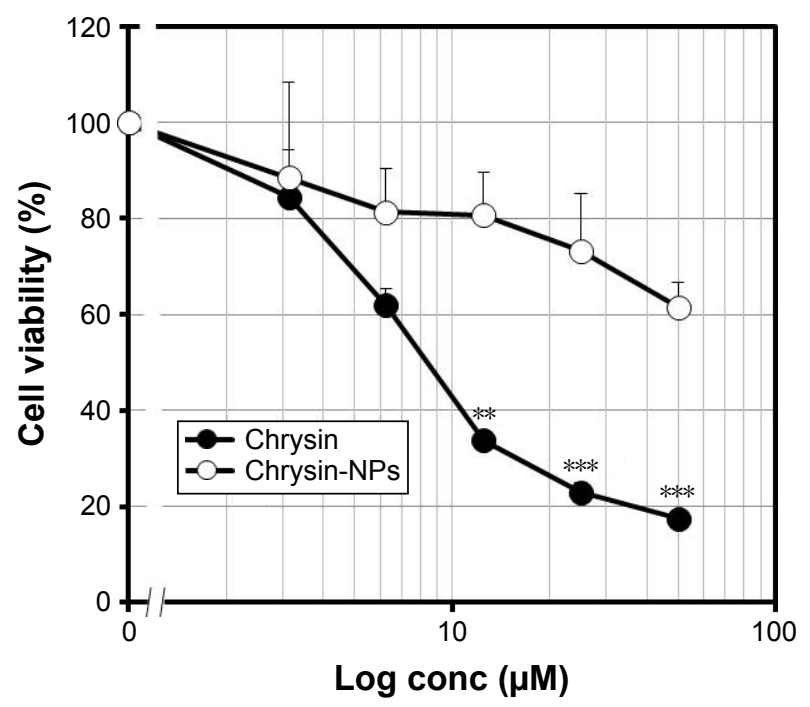

Figure 4 Cytotoxicities of chrysin-NPs and free chrysin in A549 cells.

Notes: A549 cells were treated with chrysin-NPs or free chrysin for $48 \mathrm{~h}$. Cell viabilities were assessed using a MTT assay. Data shows mean \pm SD $(n=8)$. Significance was determined using the 2-tailed Student's $t$-test. ${ }^{*} * P<0.01$, $* * * P<0.001$. Abbreviations: NPs, nanoparticles; SD, standard deviation; conc, concentration. model. Chrysin $(50 \mathrm{mg} / \mathrm{kg})$ was p.o. administrated once a day, 5 times per week because of its insoluble nature. On the other hand, chrysin-NPs were intravenously injected every 2 days, 3 times per week at $5 \mathrm{mg} / \mathrm{kg}$. Despite the dosage difference, chrysin-NPs delayed tumor growth to the same extent as chrysin (Figure 5A), and tumor weights in the chrysin-NP- and chrysin-treated groups reduced compared with the control group (Figure 5B). However, intergroup differences were not significantly shown because intragroup variation was large in the control group.

\section{Inhibited proliferation and apoptosis induction by chrysin-NPs}

For elucidating the therapeutic mechanism of chrysin-NPs, we observed Ki-67 expression as a marker of proliferation in tumor tissues. As shown in Figure 6A, cells stained with DAPI were not different among each group, but Ki-67 expression was lower in the chrysin and chrysin-NP groups than in the control group. Chrysin-NPs were found to inhibit the proliferation of A549-derived tumors, and apoptosis induction was greater in the chrysin-NP group than in the control or chrysin groups (Figure 6B). Apoptotic cells appeared brown as indicated by black arrows. These results indicated that chrysin-NPs reduced cellular proliferation and increased apoptotic cell death. To investigate the underlying molecular mechanism, we assessed p53 and p21 levels by Western blotting (Figure 6C). P53 plays a key role in apoptosis, and p21 is a target protein of p53 and a cell cycle control factor. Thus, we investigated whether changing p53 or p21 levels inhibited proliferation or induced apoptosis in vivo. Chrysin-NPs were found to induce p53 and p21 levels versus controls. These results suggest that chrysinNPs suppressed cell proliferation and induced apoptosis via the p53-p21 pathway.

\section{Discussion}

In this study, we demonstrate that mPEG-PCL in NP form can encapsulate chrysin, improve its bioavailability, and thus, its chemotherapeutic efficacy. In particular, the chrysin-NPs produced were injectable and reduced dosage and treatment times compared with oral chrysin, as determined using a non-small-cell lung cancer A549 cell-derived xenograft model.

mPEG-PCL is biodegradable and biocompatible and is thus suitable for use in the pharmaceutical field. ${ }^{27}$ Moreover, insoluble drugs (eg, curcumin, rapamycin) can be encapsulated in $\mathrm{mPEG}-\mathrm{PCL}{ }^{28,29}$ In the present study, chrysin-NPs produced using mPEG-PCL were found to be nanosized $(66.86 \mathrm{~nm})$ 


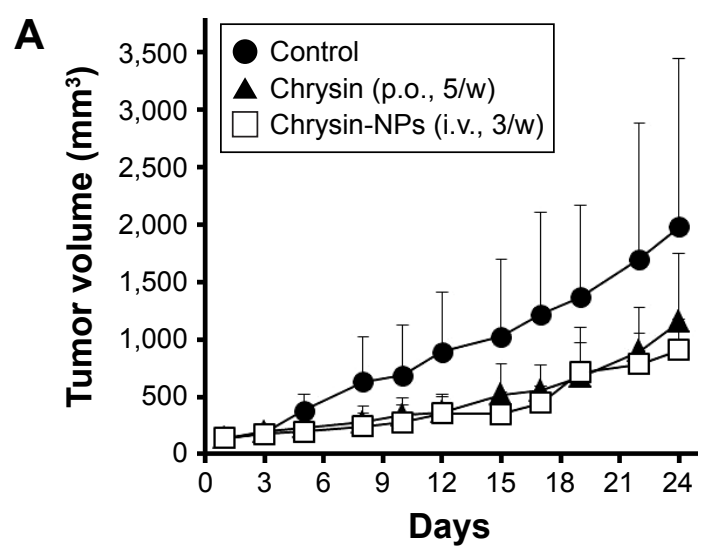

B
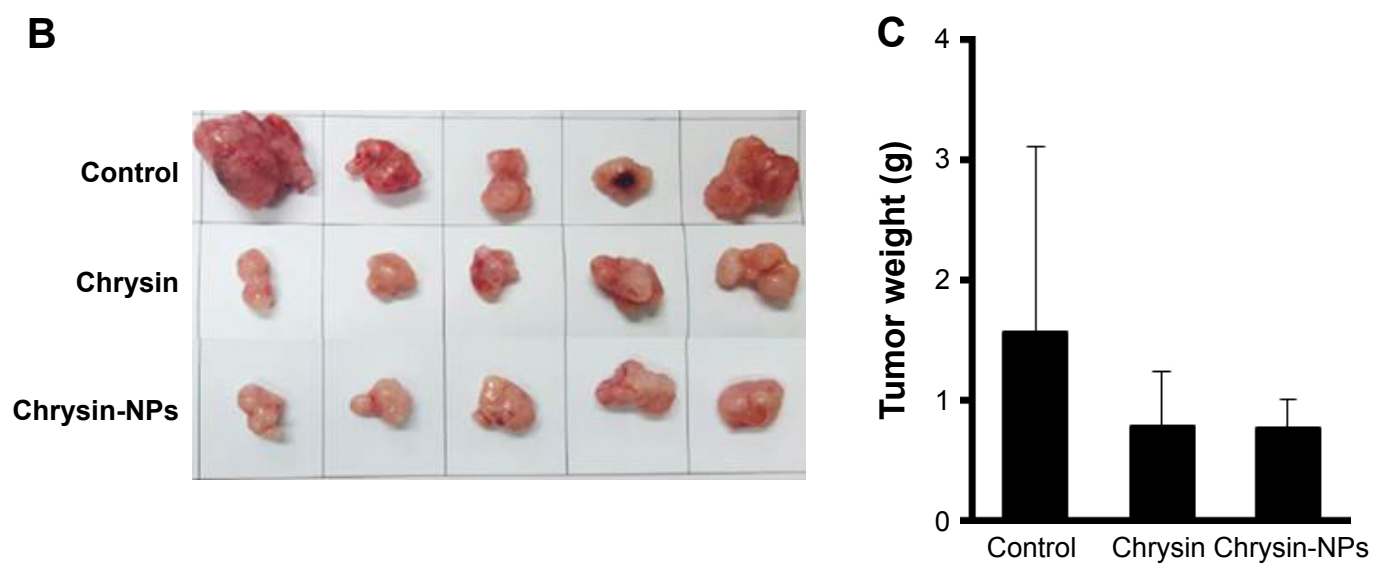

Figure 5 Suppression of tumor growth by chrysin-NPs in vivo.

Notes: Balb/c nude mice bearing an A549-derived tumor were treated with chrysin-NPs (i.v., 3 times per week) or chrysin (p.o., 5 times per week) for 3 weeks. (A) Tumor growth curve. Data shows mean \pm SD $(n=5)$. (B) Photograph of isolated tumor tissues after final tumor growth measurements. (C) Tumor weights. Data shows mean \pm SD $(n=5)$.

Abbreviations: NPs, nanoparticles; i.v., intravenous; p.o., orally; SD, standard deviation; w, week.

in water and to form micelles (Figure 2). The stability of chrysin-NP at $4^{\circ} \mathrm{C}$ was better than that at $37^{\circ} \mathrm{C}$. Thus, we stored chrysin-NPs at $4^{\circ} \mathrm{C}$ and used them within $12 \mathrm{~h}$ of preparation for experiments. Lyophilization of chrysin-NPs was not considered in this study, but it might provide a better means of longterm storage. The use of pegylated PCL is expected to prevent NPs from being engulfed by phagocytes and thus increase the in vivo half-life of chrysin. In addition, chrysin-NPs slowly released chrysin in PBS (pH 7.4) after $1 \mathrm{~h}$ (Figure 3). These results indicate that administration frequency of chrysin-NP was decreased without reduced efficacy (Figure 5).

In terms of cytotoxicity, chrysin-NPs were not as potent as free chrysin (Figure 4), indicating that chrysin-NPs might not release chrysin for cell uptake for $48 \mathrm{~h}$. However, chrysinNPs dose-dependently inhibited cell viability, suggesting that chrysin-NPs maintained the activity of chrysin. In our in vivo assay, chrysin-NPs showed significant tumor growth delay. The results showed that chrysin-NPs reduced 20 times dosage than chrysin because of injectable chrysin-NPs (Figure 5).
Suspension formulations enable delivery by intravenous (iv) injection, whereas oral administration involves absorption in the gastrointestinal track, which invariably reduces drug concentrations in blood. In pharmacokinetic studies, iv injection of chrysin resulted in higher concentrations in blood than p.o. treated chrysin. ${ }^{30}$ In a previous study, NPs were found to allow dosage reduction as was found in the present study. ${ }^{31}$ Furthermore, chrysin-NPs probably accumulate in tumor tissues due to their enhanced permeability and retention (EPR) effect.

The anticancer effects of chrysin have been reported in various cancer cell lines..$^{14,16,32}$ In the present study, chrysinNPs were observed to have anticancer effects in A549-derived tumor tissues. In fact, chrysin-NPs inhibited cell proliferation and induced apoptosis in tumor tissues (Figure 6). In our previous study, we reported that chrysin induced the apoptosis-related factors $\mathrm{p} 53$, p21, and cytochrome C in A549 cells. ${ }^{15}$ Thus, we investigated the effects of chrysin-NPs on p53 and 21 protein levels in A549-derived tumor tissues. As was expected, chrysin-NPs increased the levels of p53 and 

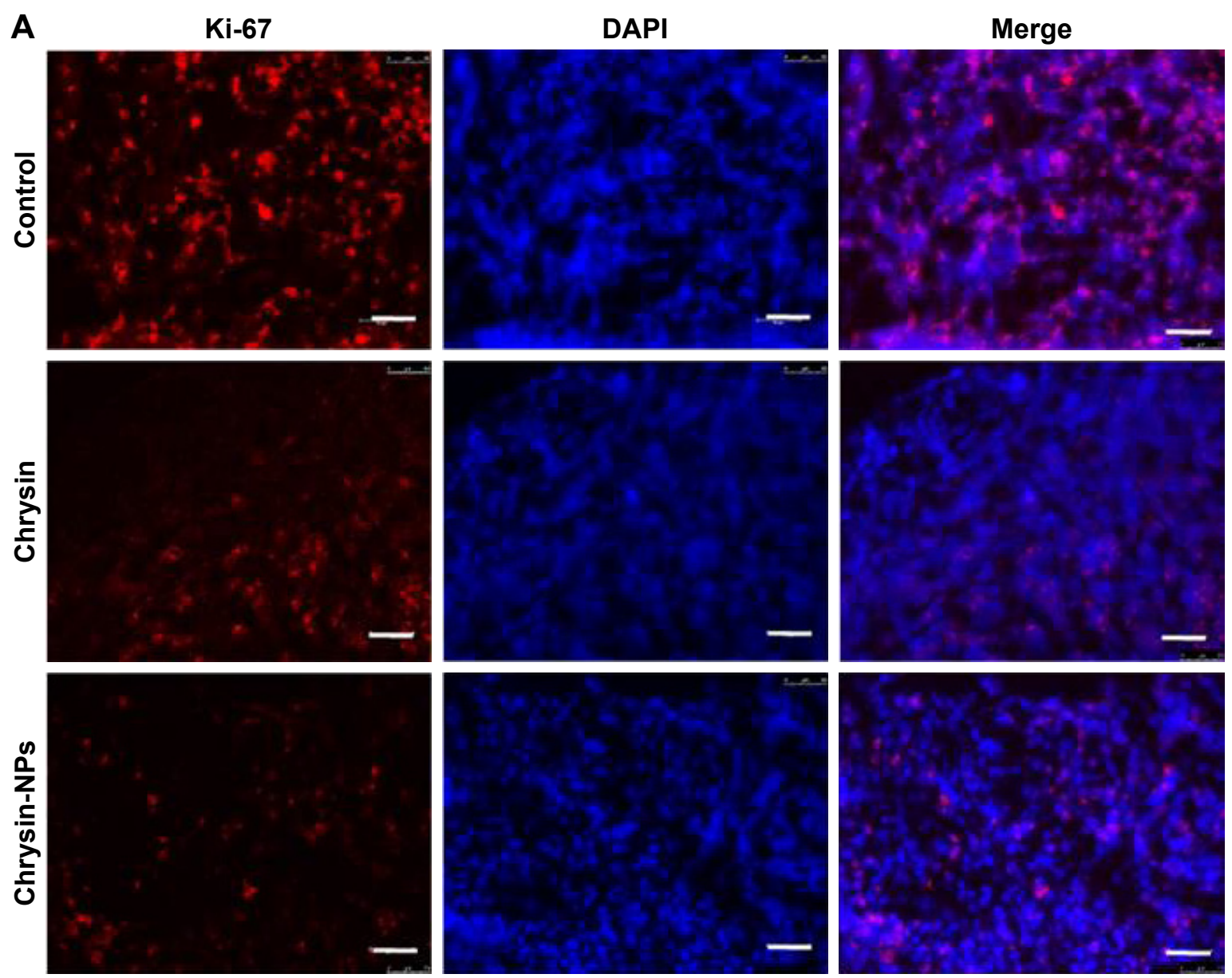

B

\section{Control}

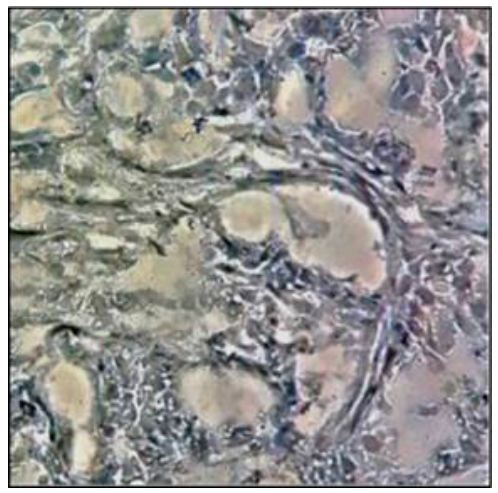

\section{Chrysin}

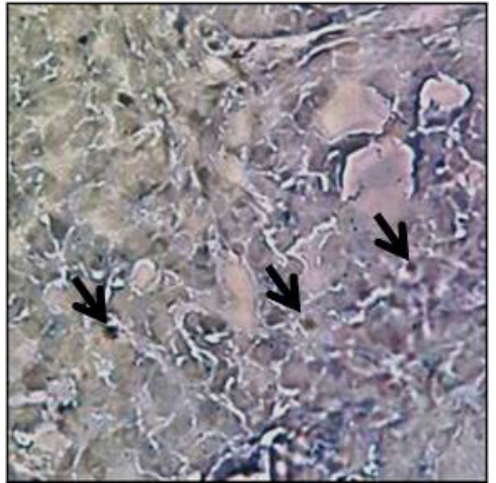

\section{Chrysin-NPs}

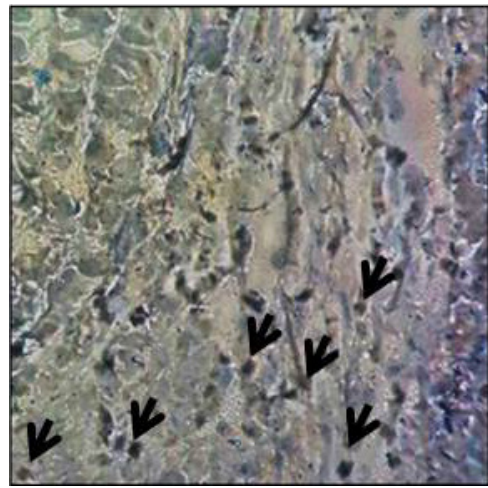

C

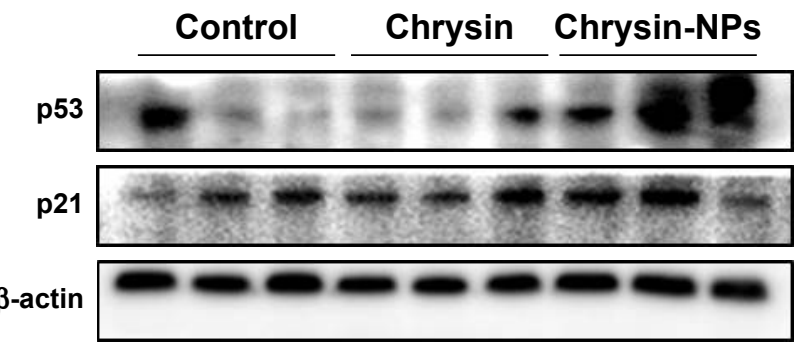

Figure 6 Anticancer effects of chrysin-NPs in A549-derived tumor tissues.

Notes: (A) Suppression of proliferation by chrysin-NPs. Ki-67 was used as a marker of proliferation (red). Scale bar $=50 \mu \mathrm{m}$. (B) Chrysin-NP induced apoptosis as observed by TUNEL assay. Brown spots represent apoptotic cells (black arrows). (C) Inductions of p53 and p2I proteins by chrysin-NPs. 
p21 (Figure 6C). These results showed that chrysin-NPs, like chrysin, induced apoptosis via the p53-p21 pathway in vivo.

\section{Conclusion}

Chrysin-NPs were found to enable administration of chrysin by injection and to improve the bioavailability and therapeutic efficacy of chrysin in an A549-xenograft model. Our in vitro and in vivo results suggest that chrysin-NPs have potential use as a chemotherapeutic agent.

\section{Acknowledgments}

This research was supported by Priority Research Centers Program through the National Research Foundation of Korea (NRF) funded by the Ministry of Education, Science and Technology (2016R1A6A1A03007648), a grant from the NRF (2014R1A1A3049498) and the Bio \& Medical Technology Development Program of the National Research funded by the Ministry of Science, ICT \& Future Planning (2015M3A9B6074045 and 2015M3A9B6073827).

\section{Disclosure}

The authors report no conflicts of interest in this work.

\section{References}

1. Shin A, Oh CM, Kim BW, Woo H, Won YJ, Lee JS. Lung cancer epidemiology in Korea. Cancer Res Treat. Epub 2016 Sep 27.

2. Premratanachai $P$, Chanchao C. Review of the anticancer activities of bee products. Asian Pac J Trop Biomed. 2014;4:337-344.

3. Yao J, Jiang M, Zhang Y, Liu X, Du Q, Feng G. Chrysin alleviates allergic inflammation and airway remodeling in a murine model of chronic asthma. Int Immunopharmacol. 2016;32:24-31.

4. Shen Y, Tian P, Li D, et al. Chrysin suppresses cigarette smokeinduced airway inflammation in mice. Int J Clin Exp Med. 2015;8(2): 2001-2008.

5. Souza LC, Antunes MS, Filho CB, et al. Flavonoid Chrysin prevents age-related cognitive decline via attenuation of oxidative stress and modulation of BDNF levels in aged mouse brain. Pharmacol Biochem Behav. 2015;134:22-30.

6. Wang J, Zhang T, Du J, Cui S, Yang F, Jin Q. Anti-enterovirus 71 effects of chrysin and its phosphate ester. PLoS One. 2014;9(3):e89668.

7. Freitas JV, Gaspar LR. In vitro photosafety and efficacy screening of apigenin, chrysin and beta-carotene for UVA and VIS protection. Eur J Pharm Sci. 2016;89:146-153.

8. Aksu EH, Ozkaraca M, Kandemir FM, et al. Mitigation of paracetamolinduced reproductive damage by chrysin in male rats via reducing oxidative stress. Andrologia. 2016;48(10):1145-1154.

9. Mantawy EM, El-Bakly WM, Esmat A, Badr AM, El-Demerdash E. Chrysin alleviates acute doxorubicin cardiotoxicity in rats via suppression of oxidative stress, inflammation and apoptosis. Eur J Pharmacol. 2014;728:107-118.

10. Samarghandian S, Azimi-Nezhad M, Samini F, Farkhondeh T. Chrysin treatment improves diabetes and its complications in liver, brain, and pancreas in streptozotocin-induced diabetic rats. Can JPhysiol Pharmacol. 2016;94(4):388-393.

11. Oliveira GA, Ferraz ER, Souza AO, Lourenco RA, Oliveira DP, Dorta DJ. Evaluation of the mutagenic activity of chrysin, a flavonoid inhibitor of the aromatization process. $J$ Toxicol Environ Health A. 2012;75(16-17):1000-1011.
12. Gambelunghe C, Rossi R, Sommavilla M, et al. Effects of chrysin on urinary testosterone levels in human males. J Med Food. 2003;6(4): 387-390.

13. Samarghandian S, Azimi-Nezhad M, Borji A, et al. Inhibitory and cytotoxic activities of chrysin on human breast adenocarcinoma cells by induction of apoptosis. Pharmacogn Mag. 2016;12(Suppl 4):S436-S440.

14. Zhang Q, Ma S, Liu B, Liu J, Zhu R, Li M. Chrysin induces cell apoptosis via activation of the $\mathrm{p} 53 / \mathrm{Bcl}-2 /$ caspase-9 pathway in hepatocellular carcinoma cells. Exp Ther Med. 2016;12(1):469-474.

15. Lim HK, Kim KM, Jeong SY, Choi EK, Jung J. Chrysin increases the therapeutic efficacy of docetaxel and mitigates docetaxel-induced edema. Integr Cancer Ther. Epub 2016 May 5.

16. Xia Y, Lian S, Khoi PN, et al. Chrysin inhibits tumor promoter-induced MMP-9 expression by blocking AP-1 via suppression of ERK and JNK pathways in gastric cancer cells. PLoS One. 2015;10(4):e0124007.

17. Kheiri Manjili H, Ghasemi P, Malvandi H, Mousavi MS, Attari E, Danafar H. Pharmacokinetics and in vivo delivery of curcumin by copolymeric mPEG-PCL micelles. Eur J Pharm Biopharm. Epub 2016 Oct 15.

18. Li X, Huang JM, Wang JN, Xiong XK, Yang XF, Zou F. Combination of chrysin and cisplatin promotes the apoptosis of Hep G2 cells by up-regulating p53. Chem Biol Interact. 2015;232:12-20.

19. Kasala ER, Bodduluru LN, Barua CC, Gogoi R. Chrysin and its emerging role in cancer drug resistance. Chem Biol Interact. 2015;236:7-8.

20. Smith CM, Graham RA, Krol WL, et al. Differential UGT1A1 induction by chrysin in primary human hepatocytes and HepG2 Cells. J Pharmacol Exp Ther. 2005;315(3):1256-1264.

21. Jung J. Emerging utilization of chrysin using nanoscale modification. J Nanomater. 2016;2016:1-7.

22. Leon IE, Cadavid-Vargas JF, Tiscornia I, et al. Oxidovanadium(IV) complexes with chrysin and silibinin: anticancer activity and mechanisms of action in a human colon adenocarcinoma model. $J$ Biol Inorg Chem. 2015;20(7):1175-1191.

23. Leon IE, Cadavid-Vargas JF, Resasco A, et al. In vitro and in vivo antitumor effects of the VO-chrysin complex on a new three-dimensional osteosarcoma spheroids model and a xenograft tumor in mice. $J$ Biol Inorg Chem. 2016;21(8):1009-1020.

24. Zheng H, Li S, Pu Y, Lai Y, He B, Gu Z. Nanoparticles generated by PEG-Chrysin conjugates for efficient anticancer drug delivery. Eur $J$ Pharm Biopharm. 2014;87(3):454-460.

25. Mohammadinejad S, Akbarzadeh A, Rahmati-Yamchi M, et al. Preparation and evaluation of chrysin encapsulated in PLGA-PEG nanoparticles in the T47-D breast cancer cell line. Asian Pac J Cancer Prev. 2015;16(9): 3753-3758.

26. Mohammadian F, Abhari A, Dariushnejad H, et al. Upregulation of Mir-34a in AGS gastric cancer cells by a PLGA-PEG-PLGA chrysin nano formulation. Asian Pac J Cancer Prev. 2015;16(18):8259-8263.

27. Wang X, Hu H, Wang $\mathrm{W}$, et al. Antibacterial modification of an injectable, biodegradable, non-cytotoxic block copolymer-based physical gel with body temperature-stimulated sol-gel transition and controlled drug release. Colloids Surf B Biointerfaces. 2016;143:342-351.

28. Liu H, Xu H, Jiang Y, et al. Preparation, characterization, in vivo pharmacokinetics, and biodistribution of polymeric micellar dimethoxycurcumin for tumor targeting. Int J Nanomedicine. 2015;10:6395-6410.

29. Wu W, He Z, Zhang Z, Yu X, Song Z, Li X. Intravitreal injection of rapamycin-loaded polymeric micelles for inhibition of ocular inflammation in rat model. Int J Pharm. 2016;513(1-2):238-246.

30. Walle T, Otake Y, Brubaker JA, Walle UK, Halushka PV. Disposition and metabolism of the flavonoid chrysin in normal volunteers. $\mathrm{Br} J$ Clin Pharmacol. 2001;51(2):143-146.

31. Woo HN, Chung HK, Ju EJ, et al. Preclinical evaluation of injectable sirolimus formulated with polymeric nanoparticle for cancer therapy. Int J Nanomedicine. 2012;7:2197-2208.

32. Laishram S, Moirangthem DS, Borah JC, et al. Chrysin rich Scutellaria discolor Colebr. induces cervical cancer cell death via the induction of cell cycle arrest and caspase-dependent apoptosis. Life Sci. 2015;143: $105-113$. 


\section{Supplementary materials}

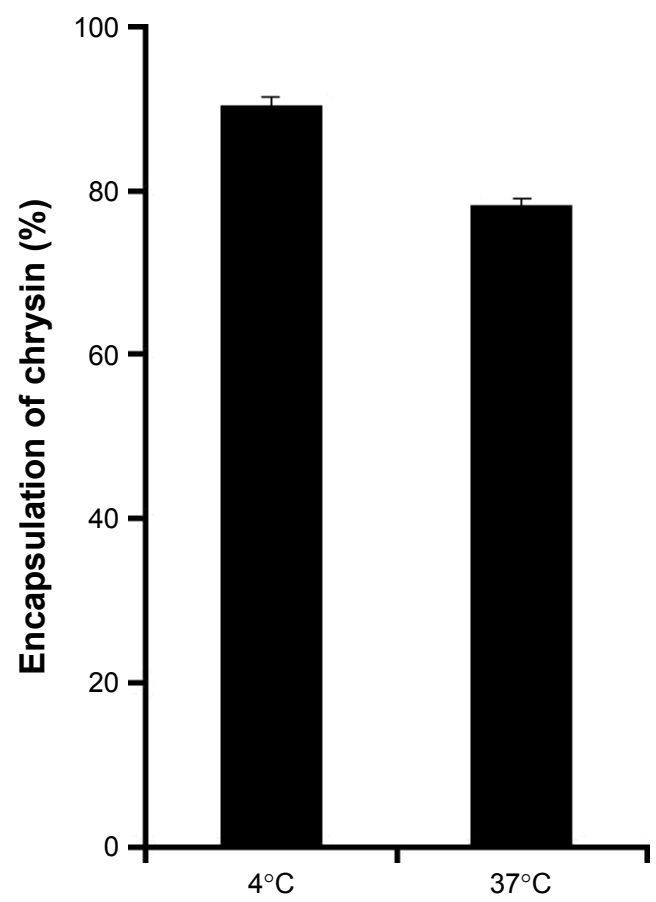

Figure SI Stability of chrysin-NPs

Notes: Chrysin-NPs were stored at $4^{\circ} \mathrm{C}$ and $37^{\circ} \mathrm{C}$ for $12 \mathrm{~h}$. Encapsulating percentage of chrysin-NPs was detected.

Abbreviation: NPs, nanoparticles.

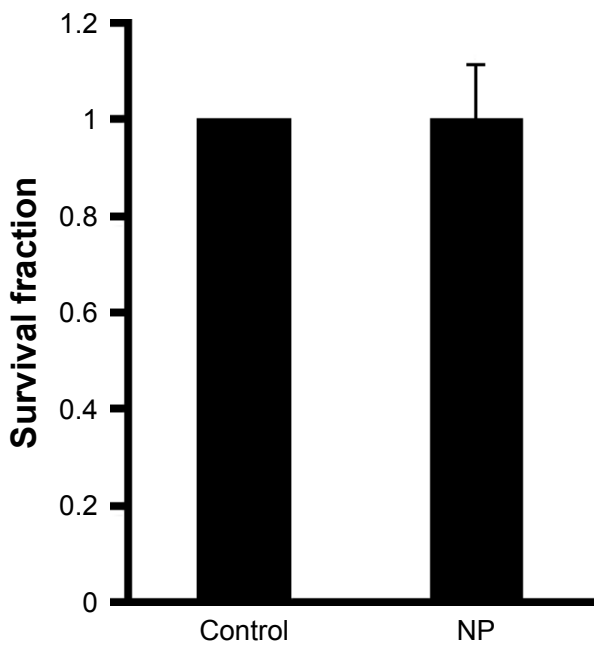

Figure S2 No toxicity of NPs.

Notes: A549 cells (100 cells/well) were seeded in 6-well plate. After 24 h, NPs were added into media of A549 cells for 12 days. In clonogenic assay, colonies were counted and survival fraction was calculated.

Abbreviation: NPs, nanoparticles.
International Journal of Nanomedicine

\section{Publish your work in this journal}

The International Journal of Nanomedicine is an international, peerreviewed journal focusing on the application of nanotechnology in diagnostics, therapeutics, and drug delivery systems throughout the biomedical field. This journal is indexed on PubMed Central, MedLine, CAS, SciSearch ${ }^{\circledR}$, Current Contents ${ } /$ Clinical Medicine,

\section{Dovepress}

Journal Citation Reports/Science Edition, EMBase, Scopus and the Elsevier Bibliographic databases. The manuscript management system is completely online and includes a very quick and fair peer-review system, which is all easy to use. Visit http://www.dovepress.com/ testimonials.php to read real quotes from published authors. 